IMF Staff Papers

Vol. 48, No. 1

(c) 2001 International Monetary Fund

\title{
Crash-Free Sequencing Strategies for Financial Development and Liberalization
}

\author{
JORGE A. CHAN-LAU and ZHAOHUI CHEN ${ }^{*}$
}

This paper uses a stylized model of financial intermediation to characterize the exact circumstances along various paths of economic growth, financial development, and liberalization that can trigger a financial crisis. It shows how to avoid financial crises through proper sequencing of various financial development and liberalization measures. The results of the paper show that naive combinations of financial development and liberalization processes can give rise to financial crises. In some typical situations, in order to avoid a financial crisis, it is important that financial liberalization be accompanied by financial development, in the form of improvements in the financial sector's efficiencies. In the case of fast growing economies, financial development becomes even more imperative. [JEL E44, F3, G15]

he importance of financial liberalization and financial development in the process of economic growth was recognized early on by Goldsmith (1969), McKinnnon (1973), and Shaw (1973) among others. Well-developed financial

\footnotetext{
*Jorge A. Chan-Lau is an Economist in the International Capital Market Department of the IMF and a Fellow of the Institute of Contemporary Finance (ICF) at Shanghai Jiao Tong University. Zhaohui Chen was an Economist in the Research Department of the IMF when this paper was written; he is now the Director of the ICF and a Fellow of the National Center of Economic Research at Tsinghua University. Both authors received their doctorates from the Graduate School of Business at Columbia University. The authors thank an anonymous referee for his detailed comments on an earlier version, Eduardo Borenzstein, Peter Clark, Peter Isard, and seminar participants at Banco de la República (Colombia), the Development Research Center of the State Council of China, Tsinghua University, the 1999 Far Eastern Meetings of the Econometric Society in Singapore, the 1999 Financial Management Association Meetings in Paris, and the 1999 International Economic Association Meetings in Buenos Aires, for their helpful comments and suggestions on an earlier draft. The views expressed are those of the authors and do not necessarily represent those of the International Monetary Fund or the ICF.
} 
systems perform a number of functions that influence the process of economic development. These functions include increased risk sharing, the facilitation of information acquisition and corporate control, the reduction of transaction costs, and the efficient allocation of savings among productive activities. In fact, a growing body of empirical studies has found a positive link between financial development and long-run economic growth. ${ }^{1}$ It is not surprising, then, that policies aiming to accelerate the pace of financial development and liberalization have gained acceptance in an increasing number of countries during the last few years.

However, the recent financial crises in Asia and Russia have led to a reexamination of and a heated debate about the wisdom of the process of financial development and liberalization, both in academic and policy making circles. ${ }^{2}$ At the academic level, it has been argued that increased globalization, and hence, financial liberalization, has made countries with sound economic policies vulnerable to financial crisis driven by a number of factors, including self-fulfilling expectations (Obstfeld, 1996), herd behavior by portfolio managers (Calvo and Mendoza, 2000), or the impossibility of smoothing out local liquidity shocks owing to the incompleteness of the structure of interregional claims (Allen and Gale, 2000), among others. At the policy making level, there is an ongoing debate on normative issues. On the one side is the camp that favors imposing controls and restrictions, on the other side is the camp that argues for more rapid and complete financial development and liberalization. On the former, Joseph Stiglitz vividly describes an emerging market as a small boat in the rough sea of international capital flows, where even a well-built boat can founder. On the latter, Lawrence Summers suggests that financial markets are like the airline industry: modern planes are stronger and larger, and make flying cheaper, faster, and safer. However, when disaster strikes, the negative consequences are magnified. The way out is not to ban airplanes or the financial markets, but to further improve the industry facilities. ${ }^{3}$

Nevertheless, even those that consider that perfect and completely open financial markets are the ideal goal for most countries agree that openness cannot be achieved overnight. ${ }^{4}$ However, holding financial development in its infancy may not be the right solution: it may isolate the country from external financial shocks but it would deprive the country of the benefit of cheap international capital (and embedded technology). So the main task facing policy makers is a positive one: to find a path from an underdeveloped financial market to one of full and free participation in the international capital markets. The path can be risky, since the danger of a financial crisis may be looming menacingly along the transition. Nevertheless, countries must undergo the duress of the often troublesome "teenage" stage if they want to be part of the "adult" financial community. In this

\footnotetext{
${ }^{1}$ Levine (1997) surveys the recent literature on financial development and economic growth.

${ }^{2} \mathrm{An}$ assessment of both the theoretical and practical aspects of capital account liberalization is presented in Eichengreen and others (1999).

${ }^{3}$ The Economist, March 14, 1998.

${ }^{4}$ See the article "Seminar discusses the orderly path to capital account liberalization," IMF Survey, Vol. 27, Number 6, March 23, 1998.
} 
"teenage" stage, proper policy sequencing is essential as expressed clearly in the April 1998 "Communique of the Interim Commmittee of the Board of Governors of the International Monetary Fund:"5

The financial crisis in Asia has given heightened attention to the role of capital flows in economic development. The effects of the crisis have not negated the contribution that capital movements have made to economic progress in the Asian countries before the crisis erupted. Rather, the crisis has underscored the importance of orderly and properly sequenced liberalization of capital movements [...]

Choosing a path that steers clear of the danger of a financial crisis is a twostep process. The first step is to identify the circumstances under which a financial crisis can occur. The second step is to formulate strategies that avoid such circumstances while moving towards the goals of financial development, liberalization, and economic growth. In other words, it is necessary to establish what preconditions must be satisfied before moving forward with financial development and the liberalization of the capital account. This paper presents a model that provides a simple analytical framework that helps us to identify the circumstances under which financial liberalization can be counterproductive by creating the necessary conditions for a financial crisis. ${ }^{6}$ In addition, the model provides an explanation to the puzzling observation that recent crises have affected fast growing countries that, prior to the crisis, enjoyed access to cheap international capital markets and were considered stellar performers. Do fast growth and easy access to international capital increase the risk of a financial crisis? Contrary to common perception, we find that the answer to the first question is positive most of the time. We also discuss how growing economies can avoid a financial crisis.

The results obtained in our stylized model require that we narrowly define the concepts of financial development and liberalization, that often have broad meanings in the literature. ${ }^{7}$ Financial development is defined as improvements in the efficiency of financial intermediation. It includes two aspects: (a) Improvements in financial infrastructure that lead to reduction in the sunk cost of financial intermediation. Examples may include physical completion of bank branches, computerization, deposit insurance, the establishment of proper accounting and disclosure rules and legal framework. (b) Improvements in the operating efficiency of the intermediaries - in other words, the reduction in marginal costs of financial intermediation. Examples may include the enhancement of credit analysis and risk management skills; reforms that eliminate crony capitalism, cozy but inefficient group cross holding, and improper government subsidies and intervention, and any other reductions in costs proportional to the amount of intermediation. Financial

\footnotetext{
5International Monetary Fund Press Release No. 98/14, April 16, 1998.

${ }^{6}$ The advantage of this simplified framework is that the policy issues can be easily analyzed using a graphical approach. However, by emphasizing crisis-aversion as the overwhelming concern, the model cannot address the welfare costs and benefits associated with financial development and liberalization. The reader interested in these issues should refer to Caprio and others (1994).

${ }^{7}$ See Caprio and others (1994) and Dooley (1996).
} 
liberalization is defined as the removal of controls to allow market determination of interest rates, and/or to allow competition. Typically, liberalization of interest rates in a regime of financial repression tends to lead to an initial rise in domestic interest rates, while an increase in competition-through free entry of domestic and foreign financial institutions - tends to lead to lower domestic interest rates. Capital account liberalization also leads to free capital flows that tend to equalize domestic and foreign interest rates.

\section{The Model}

Our analysis is an extension of the financial crisis and credit crunch model presented in Chan-Lau and Chen (forthcoming), to which we refer the reader for further technical details and assumptions.

There are three risk neutral agents in the economy: an entrepreneur (borrower), a depositor (foreign or domestic creditor), and a financial intermediary. We assume that the intermediary has limited monopolistic power so that it cannot fully pass the intermediation cost on to the entrepreneur when this cost is too high. This is the usual case in most of the developing countries where competition is limited and the government regulates the interest rate to some degree. It is assumed that all the agents are risk neutral.

The entrepreneur owns the rights to a risky project as well as an illiquid asset with terminal value $E$. In our representative entrepreneur's economy, $E$ can also be interpreted as the market valuation of the fundamental strength of the economy, or the economy's collateral value in the eyes of foreign creditors. To finance the project, the entrepreneur borrows from the intermediary at the gross rate $1+i_{L}$. In case of success, the project's return is enough to pay back the loan principal and the interest. Otherwise, it returns nothing and the illiquid asset is seized by the intermediary (up to the amount of the loan plus the loan interest) and transferred to the creditor (up to the amount of the deposit plus deposit interest). The probability of success of the project depends on the effort level of the entrepreneur. If the effort level is high the probability of success of the project is $p_{H}$, otherwise it is equal to $p_{L}$, with $p_{L}<p_{H}$. The effort level depends on monitoring by the intermediary. If the intermediary monitors the loan, then the entrepreneur's effort is high, otherwise it is low. Monitoring has a broad meaning, including project screening, auditing, on-site inspection, and other corporate governance mechanisms and is costly.

The financial intermediary borrows an amount $D$ from the depositors at the gross rate $1+i_{B}$, and lends it to the entrepreneur. Its payoff is given by:

$$
\min \left\{D\left(1+i_{L}\right), E\right\}
$$

In case that $E>D\left(1+i_{B}\right)$, the intermediary can pay back the principal and interests. Otherwise, it transfers the collateral $E$ to the depositor. Thus, in our setup, the intermediary is a limited liability institution. 
The depositor can also invest in a safe asset and earn a risk-free rate of return, $i_{f}$. Because the depositor must earn at least the risk-free rate, the amount of credit he is willing to supply to the intermediary is given by:

$$
\begin{aligned}
& \bar{D}_{m}(E)=\frac{\left(1-p_{H}\right) E}{1+i_{f}-p_{H}\left(1+i_{B}\right)} . \\
& \bar{D}_{u}(E)=\frac{\left(1-p_{L}\right) E}{1+i_{f}-p_{L}\left(1+i_{B}\right)},
\end{aligned}
$$

where the subscripts $m$ and $u$ denote that monitoring is performed or not performed, respectively. The amount of intermediation under monitoring is greater than that without monitoring, and they are both increasing in the borrowing rate $i_{B}$ and decreasing in the risk-free rate. ${ }^{8}$

Monitoring loans is an activity that involves both fixed and variable costs. In our model, the costs represent the extent of the inefficiency in financial intermediation. Fixed costs include sunk costs, overhead costs, salary and wage costs, expenses in branch facilities and equipment (computers), which are typical of banking institutions, as well as costs resulting from the legal and supervisory environment, such as bankruptcy enforcement costs. Variable costs include operating and administrative costs, as well as regulatory costs resulting from mandatory reserve ratios, etc. In different country environments, these costs take different forms. ${ }^{9}$ Arguably, substantial investment in banking infrastructure in many emerging markets has made fixed costs relatively low, but operating efficiency has lagged far behind owing to inadequate staff training, obscure accounting systems, and lack of disclosure and competition. Banking costs, both fixed and variable costs, are higher in emerging market countries than in developed countries. ${ }^{10}$

Technically, we represent these costs by the following simple cost function:

$$
C(D)= \begin{cases}\phi & \text { if } D<D_{\phi}=E /\left(1+i_{L}\right)+E_{\phi}, E_{\phi} \text { constant } \\ \phi+\beta\left(D-D_{\phi}\right) & \text { if } D>D_{\phi}\end{cases}
$$

The cost is a function of the size of the loan, $D$, the entrepreneur's asset $E$, and the efficiency of the monitoring technology, which is measured by the parameter $\beta>0$ and by a fixed cost $\phi>0$ and reflect the efficiency of the intermediary. The intermediary can monitor projects requiring a loan size less than $D_{\phi}$ by paying a fixed cost of $\phi$. The depositor can observe whether the intermediary monitors or does

\footnotetext{
${ }^{8}$ For details on the derivation of these equations, see Chan-Lau and Chen (forthcoming).

${ }^{9}$ For example, in South Korea the cozy relationship between banks and chaebols implies a potentially low fixed cost of monitoring because they know each other well. However, the cost of disclosing and acting on the information gathered is potentially costly.

${ }^{10}$ See Barajas, Steiner, and Salazar (1999) for details.
} 
not monitor the entrepreneur, which makes the probability of success of the project known to all agents. There is no asymmetric information.

We focus on the case in which the amount of intermediation (or loan size) plus interest exceeds the value of the collateral, that is, $\bar{D}_{m}\left(1+i_{B}\right)>E$, which holds when $E_{\phi} / E>\Delta i /\left(1+i_{B}\right)\left(1+i_{L}\right)$. In this case, the expected profit of the intermediary is given by:

$$
\mathbf{E} \Pi^{m}(D) \equiv p_{H} \Delta i D-\max \left\{\phi, \phi+\beta\left(D-D_{\phi}\right)\right\} .
$$

Similarly, when the intermediary does not monitor, its expected profit is given by:

$$
\mathbf{E \Pi}^{u}(D) \equiv p_{L} \Delta i D
$$

Monitoring takes place only when it generates more profits than without monitoring:

$$
\Delta \mathrm{E} \Pi(D) \equiv \mathrm{E}^{m}(D)-\mathrm{E}^{u}(D)=\Delta p \Delta i D-\max \left[\phi, \phi+\beta\left(D-D_{\phi}\right)\right]>0 .
$$

The amount of the loan offered to the entrepreneur by the intermediary as well as the decision to monitor or not depend on: (a) the efficiency of the intermediary, as measured by its monitoring costs, (b) the interest rate differential, $\Delta i=i_{L}-i_{B}$, (c) the credit supply by the depositors, as defined by equations (1)-(2), and (d) the terminal value of the existing asset $E$. There exist six possible cases, which can be

\begin{tabular}{|c|c|c|c|}
\hline Case & & $\phi$ & $\beta$ \\
\hline 1 & $<\Delta p \Delta i$ & $\left.\frac{E}{1+i_{L}}+E_{\phi}\right)$ & $>p_{H} \Delta i$ \\
\hline 2 & $>\Delta p \Delta i$ & $\frac{E}{1+i_{L}}+E_{\phi}$ & $>p_{H} \Delta i$ \\
\hline 3 & $<\Delta p \Delta i$ & $\frac{E}{1+i_{L}}+E_{\phi}$ & $\Delta p \Delta i<\beta<p_{H} \Delta i$ \\
\hline 4 & $>\Delta p \Delta i$ & $\frac{E}{1+i_{L}}+E_{\phi}$ & $\Delta p \Delta i<\beta<p_{H} \Delta i$ \\
\hline 5 & $<\Delta p \Delta i$ & $\frac{E}{1+i_{L}}+E_{\phi}$ & $<\Delta p \Delta i$ \\
\hline 6 & $>\Delta p \Delta i$ & $\left.\frac{E}{1+i_{L}}+E_{\phi}\right)$ & $<\Delta p \Delta i$ \\
\hline
\end{tabular}
classified according to the magnitude of various monitoring costs relative to the interest rate differential and the value of the illiquid asset: 11

\footnotetext{
${ }^{11}$ These cases and their corresponding choice of monitoring action and deposit demand by the intermediary are analyzed in detail in the appendix.
} 
Figure 1. Case 1-A Mechanism for Financial Crisis

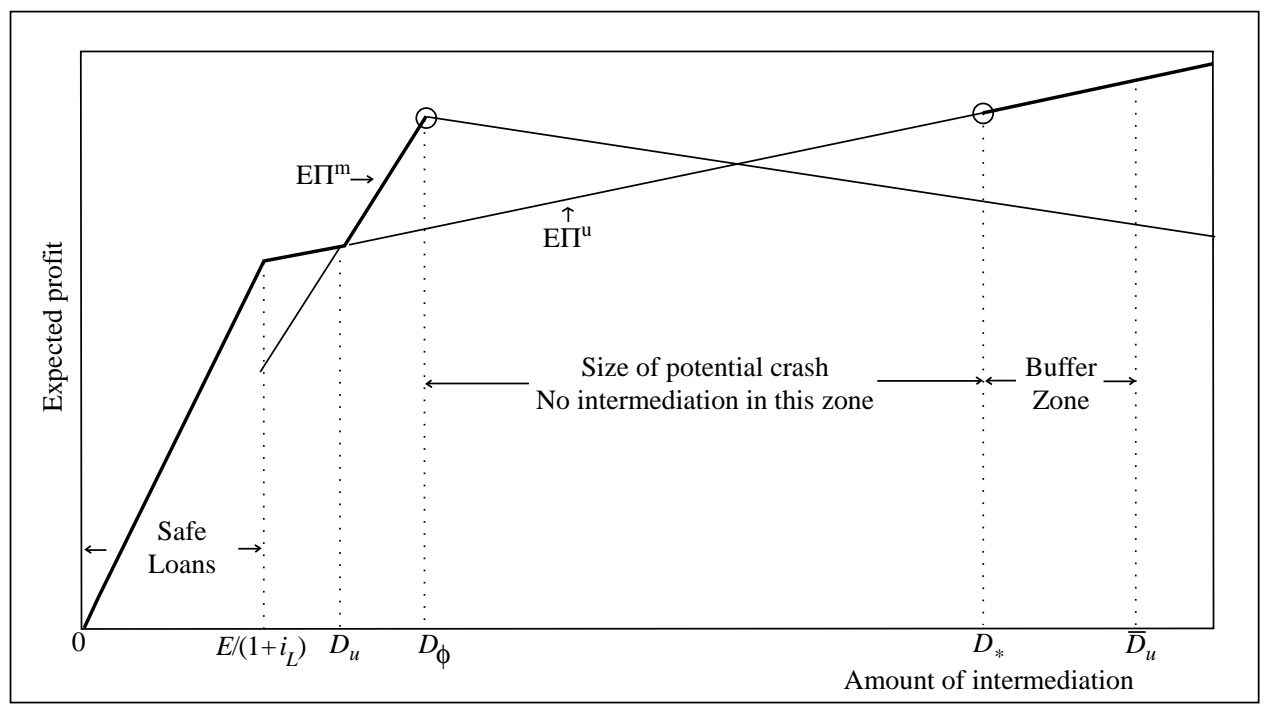

In Case 1 the economy is vulnerable to the risk of financial crisis or crash, which is defined as the sudden discrete reversal of capital inflows into the banking system, a phenomenon that resembles a credit crunch. Formally, this crisis-prone equilibrium can be defined as one in which there is an insufficient demand for credit by the intermediary. A formal definition of this and other equilibria is presented in the appendix. It is easy to describe the crisis-prone equilibrium using Figure 1. The thick lines represent the expected profit to the financial intermediary, with a local maximum at the point $D_{\phi}$, which is the optimal amount of intermediation with monitoring. $\bar{D}_{u}$ is the maximum supply of credit by the depositor and depends positively upon a measure of the fundamental strength of the economy $E$. An important feature of this model is that a small change in credit supply can trigger a large capital outflow and/or credit crunch. From Figure 1, we can see that the amount of equilibrium intermediation (when demand for credit equals credit supply) can increase, unmonitored, after the switching point $D_{*}$. When credit supply is between $D_{\phi}$ and $D_{*}$, however, there is no demand by the intermediary because its expected profit is below the local maximum, so the intermediary borrows only $D_{\phi}$. So even when $\bar{D}_{u}$ declines to a level marginally below $D_{*}$, the size of capital outflow is as large as $D_{*}-D_{\phi}$.

In this work, we are more concerned about the process of financial development, financial liberalization, and economic growth, so the economy would be able to switch from one case to another as the interest rate differential, the costs parameters, and fundamental strength change. In our simplified setup, the narrowing of the interest rate differential results from the process of financial liberalization while the reduction of the monitoring costs are the consequence of 
the financial reform process. ${ }^{12}$ It is of special interest to pinpoint the conditions under which either financial development and liberalization or both processes can put the economy at risk by shifting it to Case 1 .

The analysis is greatly simplified if the six different cases are graphed in a three-dimensional space, where the orthogonal axes correspond to the sunk cost, $\phi$, the marginal cost, $\beta$, and the interest rate differential, $\Delta i=i_{L}-i_{B}$. The boundaries among the different cases are determined by the following surfaces:

$$
\begin{array}{ll}
S_{1}: & \phi=\Delta p \Delta i D_{\phi} \\
S_{2}: & \beta=\Delta p \Delta i \\
S_{3}: & \beta=p_{H} \Delta i,
\end{array}
$$

which are depicted in Figures 2 and 3. For expositional purposes, we will refer to the region corresponding to Case 1 as Region 1, Case 2 as Region 2, and so on. In particular, Region 1 will be referred to as the crisis-prone region. Figure 2 shows the case in which the deposit rate $i_{B}$ is fixed and changes in the interest rate differential correspond to changes in the lending rate $i_{L}$. In this case, $S_{1}$ is a nonlinear surface because $\Delta i D_{\phi}$ is a nonlinear function of $i_{L}$.

In Figure 3, the lending rate $i_{L}$ is fixed and we let the deposit rate $i_{B}$ vary. In this case, $S_{1}$ is a linear function of the interest rate differential $\Delta i$. For convenience, we choose to use the interest rate differential $\Delta i$ as one of the axes instead of $i_{L}$ in Figure 2, and instead of $i_{B}$ in Figure 3. Our graphical framework does not preclude the analysis of simultaneous changes in $i_{L}$ and $i_{B}$ : first, we use Figure 2 to analyze a change in $i_{L}$ keeping $i_{B}$ fixed and afterwards, change $i_{B}$ while keeping $i_{L}$ constant at its new level.

In addition, the level of financial development in the economy at any point can be represented by the ordered pair $(\phi, \beta)$ in the $\phi-\beta$ plane. Therefore, we can represent any economy by the ordered set $(\phi, \beta, \Delta i)$, which grossly represent the degrees of financial development and financial liberalization.

\section{Financial Liberalization Unaccompanied by Financial Development}

Consider a case of financial liberalization as characterized by a decrease in $\Delta i$ due to a decrease in the lending rate, $i_{L}$. This decrease in the interest rate differential can be interpreted as a result of increasing competition in the banking sector, which erodes the monopolistic power of the domestic banking sector, or the reduction of capital account restrictions. Assuming that the borrowing rate is constant (as in the case of a small country's international borrowing), we can restrict our analysis to the situation depicted in Figure 2. If the economy is either in Region 3 or Region 5, a decrease in $\Delta i$ may lead the economy to Region 1 for

\footnotetext{
${ }^{12} \mathrm{As}$ noted earlier, liberalization of interest rates in a regime of financial repression tends to lead to an initial rise in domestic interest rates, hence the widening of the interest rate differential, whose effect can be analyzed in the model.
} 
CRASH-FREE SEQUENCING STRATEGIES

Figure 2. Possible States of the Economy (constant deposit rate)

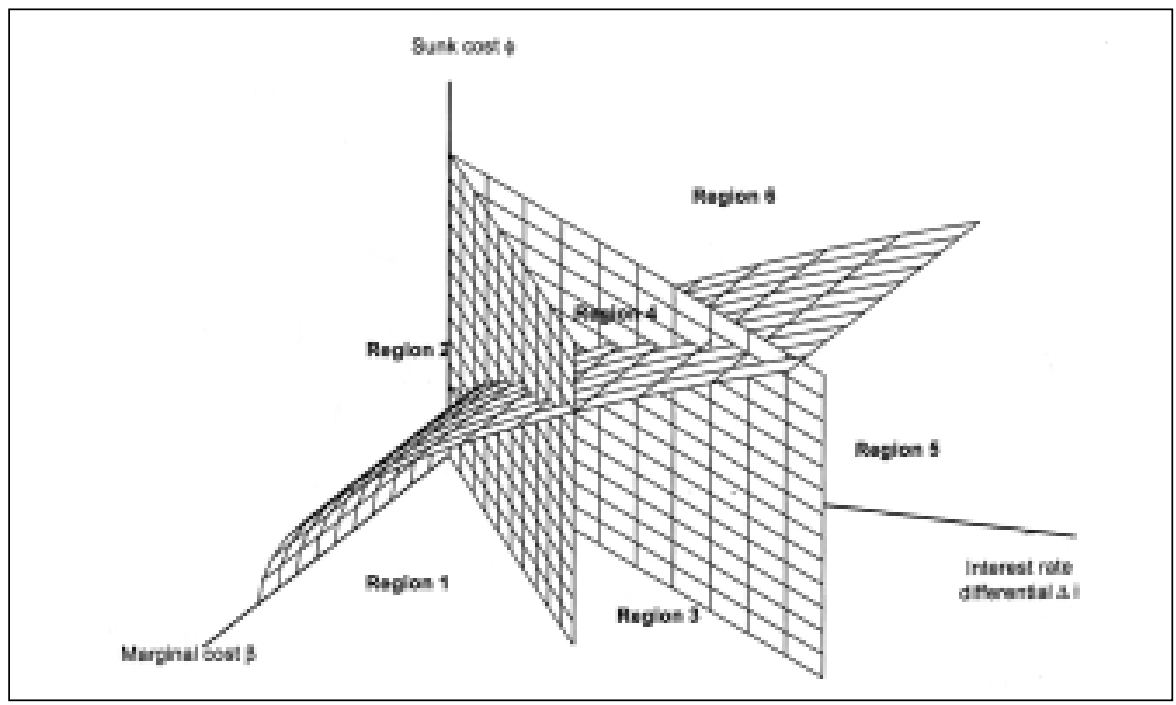

Figure 3. Possible States of the Economy (constant lending rate)

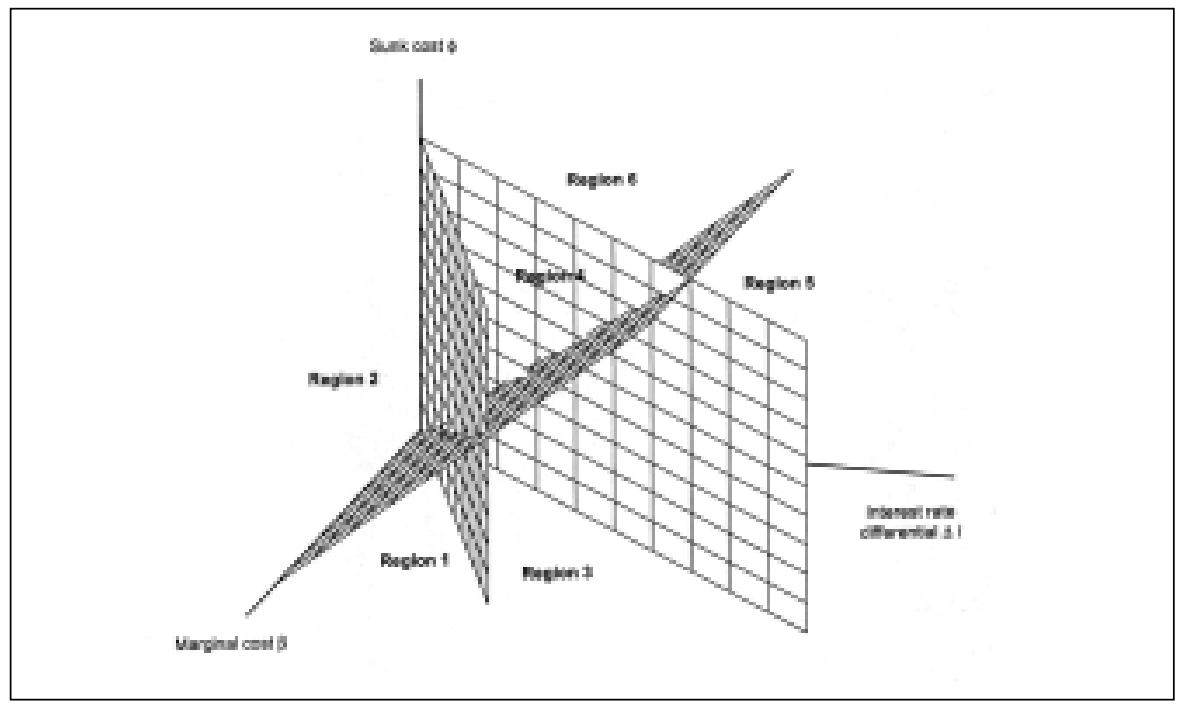


Figure 4. A Case Where Financial Liberalization Leads to a Financial Crisis

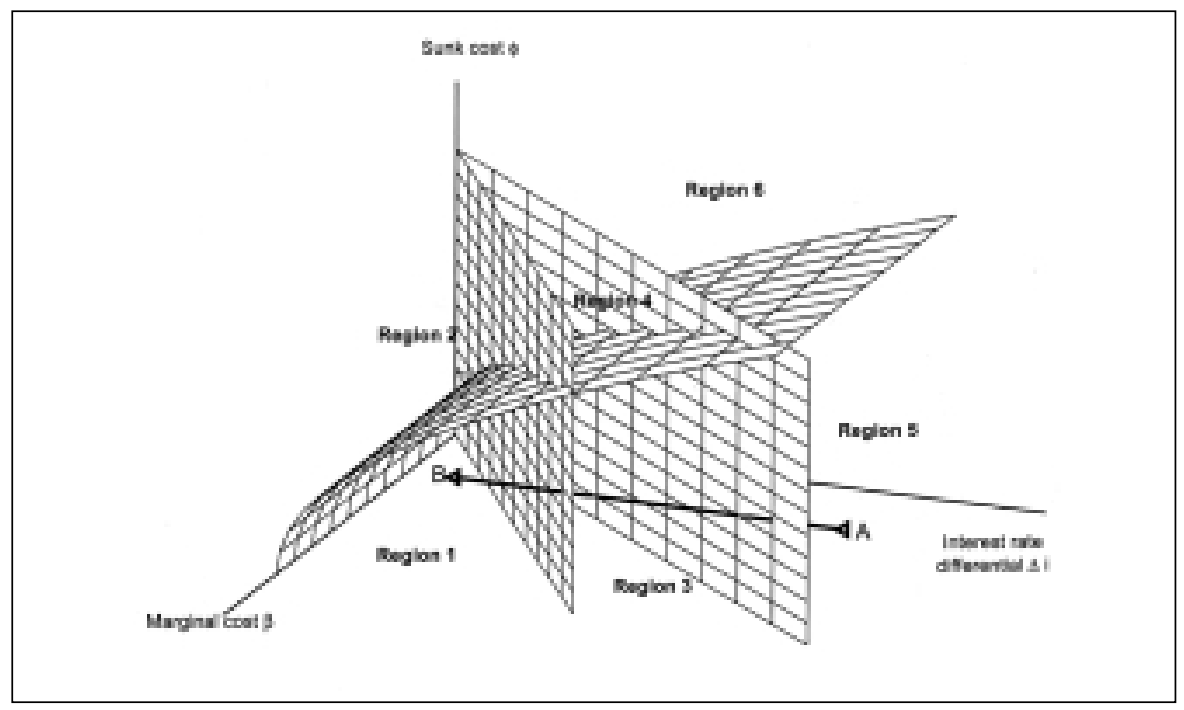

certain levels of financial development, represented as different combinations of sunk and variable costs $(\phi, \beta)$. For example, in Figure 4, financial liberalization moves the economy from point $\mathrm{A}$ to point $\mathrm{B}$, the latter inside the crisis-prone region. Thus, financial liberalization can move an economy to a situation in which it would be vulnerable to a financial crisis. The wider the range of pairs $(\phi$, $\beta$ ) the more vulnerable an economy is, since it increases the likelihood that financial liberalization can put it at risk if financial development does not complement the former process.

It is possible to characterize precisely the combination of fixed and marginal costs $(\phi, \beta)$ (or levels of financial development) such that financial liberalization may increase the vulnerability of the economy to a financial crisis or domestic crunch. It is simply the area in the $\phi-\beta$ plane that lies between the $\beta$ axis and the projection in the $\phi-\beta$ plane of the intersection between the surfaces $S_{1}$ and $S_{3}$. We can define the vulnerability region as the level of financial development, represented by the pairs $(\phi, \beta)$, such that a large enough decrease in the interest differential can move the economy to the crisis-prone region. Strictly speaking, the vulnerability region, denoted by $A_{1}$, can be represented as:

$$
A_{1}=\left\{(\phi, \beta): \phi<\frac{\beta \Delta p}{p_{H}}\left(\frac{p_{H} E}{1+\beta+p_{H} i_{B}}+E_{\phi}\right)\right\}
$$

which is the shaded region depicted in Figure 5. 
Figure 5. Financial Development: Vulnerability Region $A_{1}$

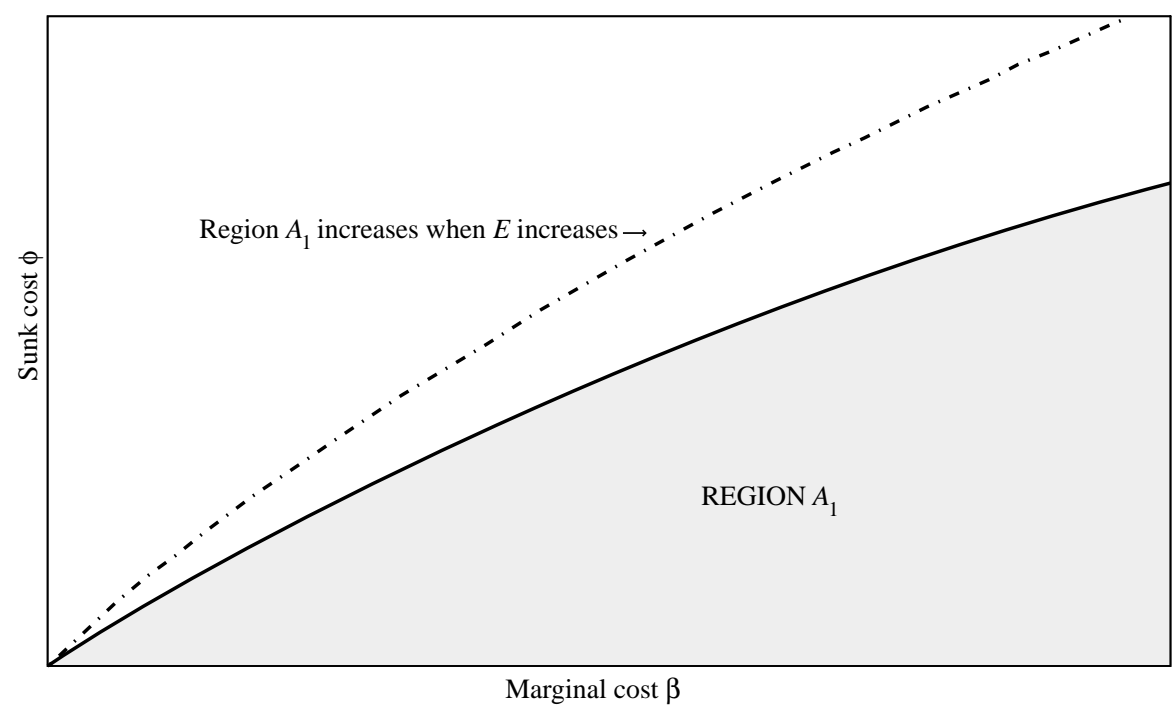

\section{Financial Development Unaccompanied by Financial Liberalization}

Under the assumption that there is no financial liberalization, and the deposit interest rate remains fixed, $\Delta i$ is constant and we can analyze the process of financial development in the $\phi-\beta$ plane, which simplifies the analysis greatly. Without loss of generality, for a given interest rate differential, the analysis is reduced to the projection of the six regions in the $\phi-\beta$ plane, as represented as in Figure 6. Notice that only the economies in Region 2 are at risk of being vulnerable to financial crisis if the process of financial development reduces the sunk cost $\phi$ faster than the variable cost $\beta$, because the economy may move from Region 2 to Region 1 as a result. Therefore, financial development must decrease the marginal operating cost faster than the fixed cost. In fact, without knowing with certainty in which region the economy is located, the safest strategy is to reduce the variable cost first, say until it is below $\Delta p \Delta i$, and then to proceed to reduce the fixed cost $\phi$. In the operational sense, this suggests that reform measures should first focus on enhancing the credit analysis and monitoring expertise and operating efficiencies of the intermediaries, rather than improving the banking infrastructure that relates only to the fixed cost aspects of financial intermediation.

Technically, if the initial position of the economy is in Region 2 and known with certainty, say, at $\left(\phi_{0}, \beta_{0}\right)$, any proper sequencing of financial reform that avoids leading the economy to Region 1 must be such that the speed of fixed and marginal cost reduction, $\partial \phi / \partial t$ and $\partial \beta / \partial t$ respectively, satisfy the following inequality: 
Figure 6. A Case Where Too Quick a Relative Reduction in Sunk Costs Leads to a Financial Crisis

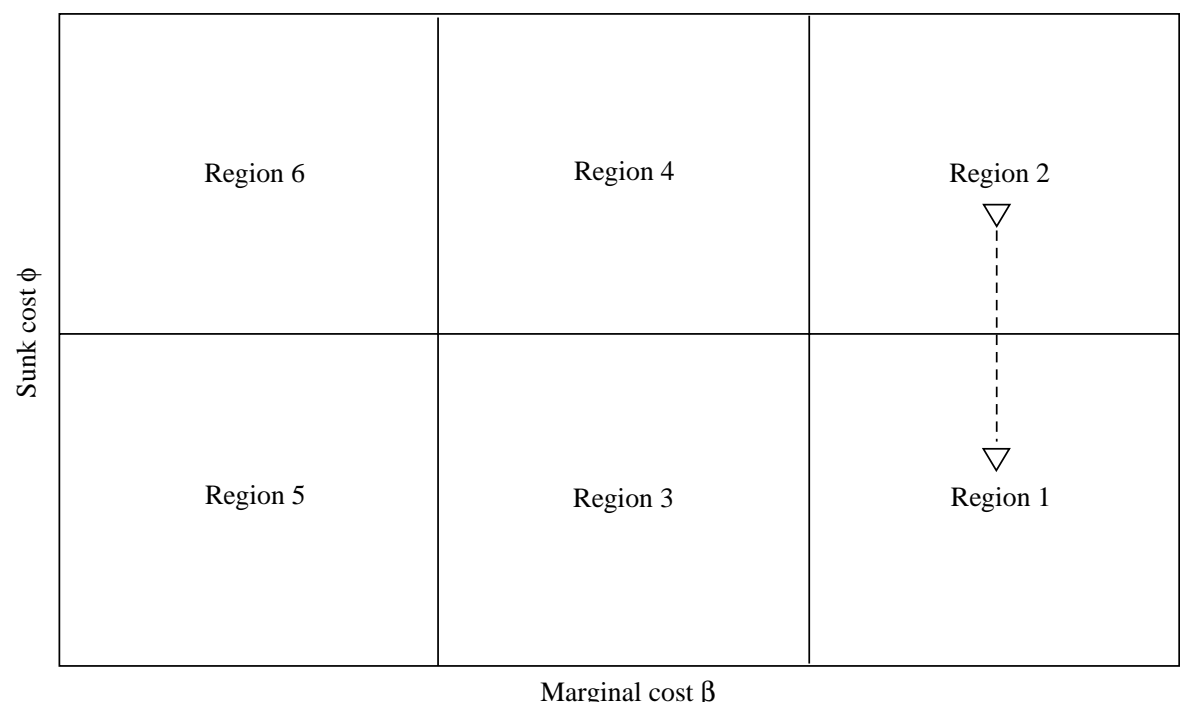

$$
\frac{\partial \beta / \partial t}{\partial \phi / \partial t} \geq \frac{\beta_{0}-p_{H} \Delta i}{\phi_{0}-\Delta p \Delta i D_{\phi}}
$$

Of course, if the initial position is outside both Region 1 and Region 2, then any sequencing of financial development is fine, without the danger of a financial crisis.

To summarize, in the absence of financial liberalization, the choice of sequencing is reduced to the relative speed of financial developments in the two fronts: one that reduces the fixed costs of intermediation, the other that reduces the marginal costs of intermediation. When the current efficiency position is in doubt, it is always safer to embark on operating efficiencies first.

\section{Financial Development and Liberalization}

The proper sequencing of financial development and liberalization must be such that the trajectory of the economy avoids the crisis-prone region depicted in Figures 2 and 3. Because there exist many different trajectories corresponding to different financial development and liberalization measures such that the crisisprone region can be avoided, policy makers have many degrees of freedom to choose the one that minimizes their cost-benefit trade-off, according to their own policy goals. As an example, suppose that the sunk cost, $\phi$, is fixed and the economy is originally located in point $A$, as shown in Figure 7. 
Figure 7. Two Examples of Crash-Free Sequencing Strategies

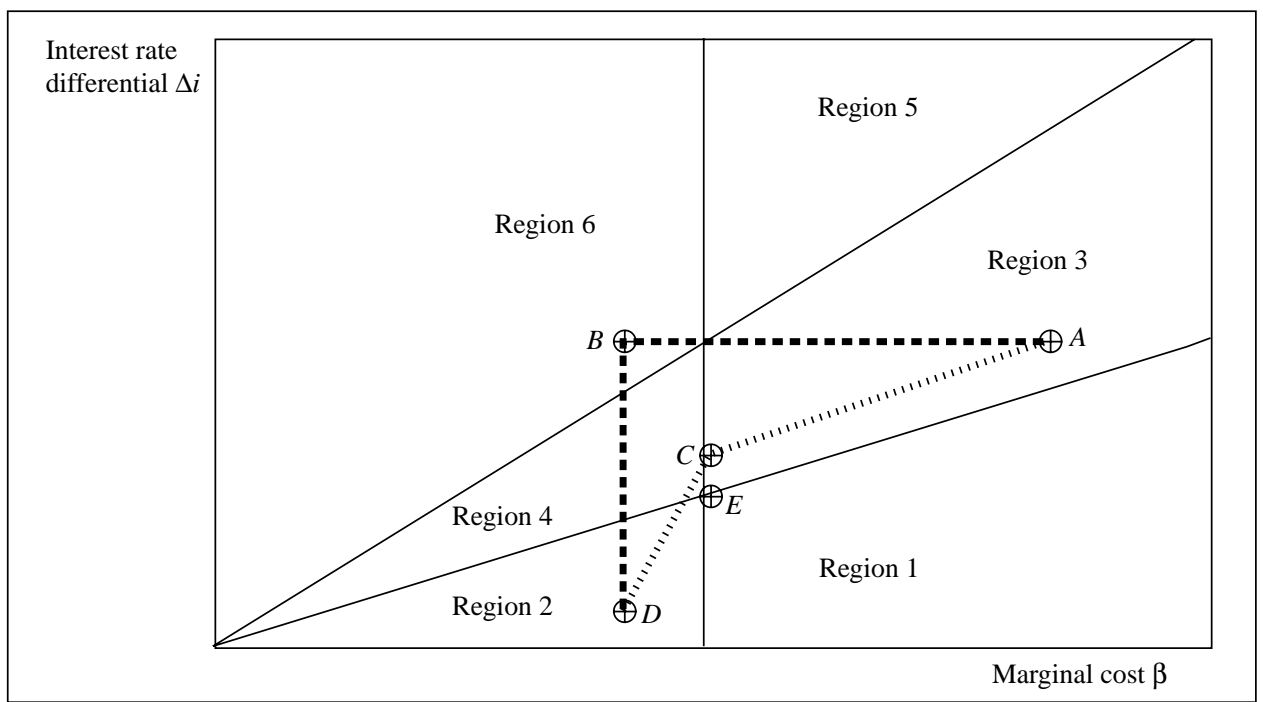

If the desired goals of liberalization and reform must be such that the final position of the economy is at point $D$, there are many ways to achieve this objective. One of them is to start the financial development process first while delaying financial liberalization until the reform objectives have been achieved. This is illustrated by the trajectory $A B D$. Another way to proceed is to start both financial development and liberalization simultaneously, such that the speed of financial development is faster than the speed of liberalization, that is, the slope of the segment $\overline{A C}$ is flatter than that of the segment $\overline{A E}$. Once the economy has reached point $D$, it is safe to start reducing the fixed cost component.

In general, when the policy maker is uncertain about the economy's current position, the safest way to proceed is to develop the financial sector first and then to undertake financial liberalization. Financial development should start by decreasing the marginal cost component of the financial intermediation sector, and then proceed to reduce the fixed cost component. We must keep in mind, though, that the sequencing described does not guarantee a crash-free evolution, since the economy is still subject to deposit rate shocks and shocks to the fundamental strengths of the economy. The effects of these shocks are discussed in the following two sections.

\section{Shocks to the Deposit Rate $i_{B}$}

Consider the case of financing by foreign deposits. Assuming that all the other variables remain constant, shocks to the world interest rate, $i_{B}$, can be interpreted as changes in the interest rate differential, $\Delta i$. The analysis then is analogous to the 
case where financial liberalization precedes financial development, with the vulnerability region, $A_{1}$, redefined as:

$$
A_{1}=\left\{(\phi, \beta): \phi<\frac{\beta \Delta p}{p_{H}}\left(\frac{E}{1+i_{L}}+E_{\phi}\right)\right\}
$$

Referring to Figure 3, an increase in the deposit rate, $i_{B}$, keeping $i_{L}$ constant, is equivalent to a narrowing of the interest rate differential, $\Delta i$, and for some economies lying in Regions 3 and 5, it can move them to Region 1, depending on whether their level of financial development, represented by their ordered pairs $(\phi$, $\beta)$, lies in the vulnerability region defined in equation (8).

As in the previous case, an increase in the market valuation of a country's economic strength, $E$, increases the extent of the vulnerability region, $A_{1}$. In contrast, an increase in the domestic lending rate, $i_{L}$, reduces the region $A_{1}$ and therefore, reduces vulnerability to a crisis, other things being equal.

\section{Economic Growth and Financial Crisis}

To answer the question why high-growth countries are not immune to financial crisis, we first examine the case of financial liberalization unaccompanied by financial development. In our model, a fast growing economy is characterized by a fast growing value of $E$. Recall the definition for the crisis-prone region, reproduced below for easy reference:

$$
A_{1}=\left\{(\phi, \beta): \phi<\frac{\beta \Delta p}{p_{H}}\left(\frac{p_{H} E}{1+\beta+p_{H} i_{B}}+E_{\phi}\right)\right\}
$$

Clearly, the extent of region $A_{1}$ depends on the market valuation of the fundamental strength of the economy, $E$. An increase in $E$ enlarges the region $A_{1}$ and hence, increases the vulnerability to a financial crisis under financial liberalization. Furthermore, typically, a fast growing economy will be characterized by a high value of $E$ and cheaper access to the world capital markets, which implies a lower borrowing rate $i_{B}$. The combination of these two factors can increase the vulnerability of a country to a crisis if financial development does not take place.

When economic growth, financial development, and financial liberalization proceed simultaneously, the interaction becomes very complex, and the right sequencing of financial development and liberalization must be designed such that financial crises are avoided.

Figure 8 shows the effects of an increase in $E$. This increase shifts up the surface $S_{1}$, increasing the size of Regions 1, 3, and 5. Thus, economic growth can put at risk economies that were previously in a safe region, such as those that were originally situated in Region 2 but that now lie in Region 1 as a result of the increase in $E$. For example, economies previously located in subregion $A$ are now in the crisis-prone region after an increase in $E$. In consequence, financial devel- 
Figure 8. The Curse of Growth: Safe Subregion $A$ in Crisis Region After an Increase in $E$

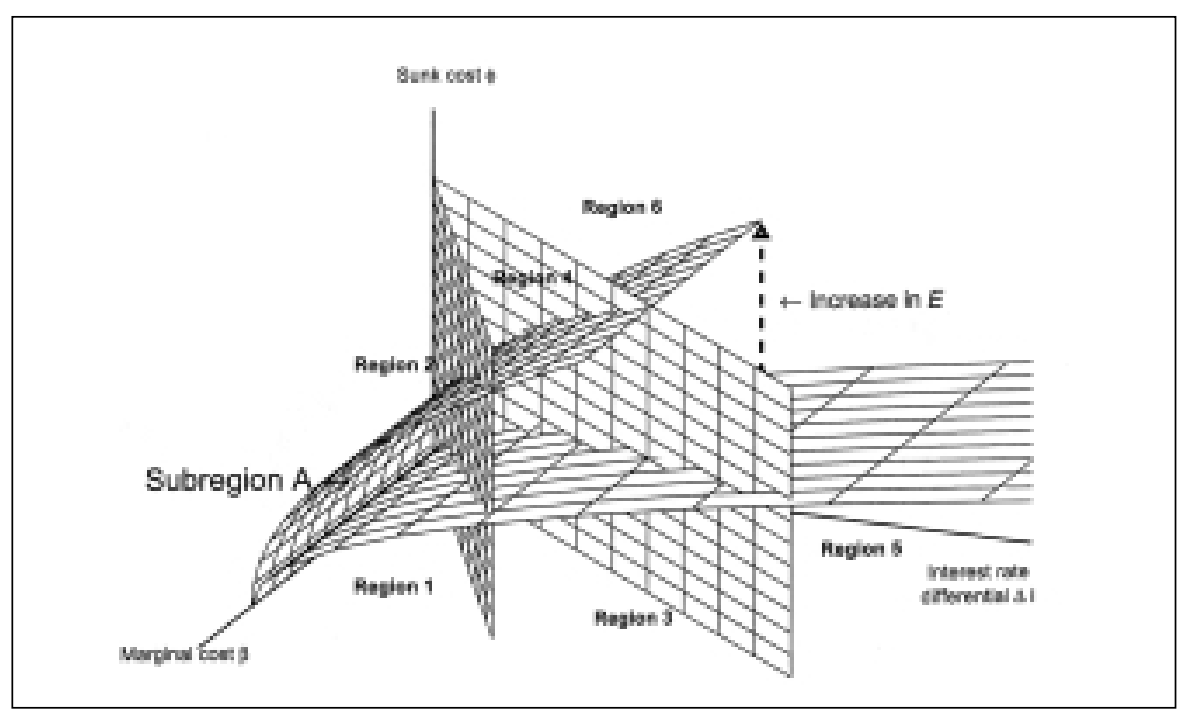

opment is an even more urgent task in fast growing economies and should not be put off for any reason: for any fixed combination of $(\phi, \beta)$, fast growth would keep increasing the market valuation $E$ until the economy is swallowed by the everenlarging crisis-prone region. Thus, if a country starts liberalizing its financial sector during a period of rapid growth, it must undertake rigorous structural reforms of its financial sector first or at least at a faster pace than the liberalization process.

\section{Concluding Remarks}

This paper has developed a model of financial intermediation that offers some interesting insights into the interaction among economic growth, financial development, financial liberalization, and the occurrence of financial crisis. By identifying basic stylized inefficiencies of the financial sector, it is possible to derive simple graphical tools that enhance our understanding about how naive combinations of financial development and liberalization can give rise to a financial crisis. In particular, in the case of fast growing economies, financial development aimed at improving the efficiencies of the financial sector becomes even more imperative.

The analysis also highlights the fact that there are many different ways to conduct an orderly sequencing of financial development and liberalization, such that crises can be avoided. The preferred sequencing process would depend on the objective functions of the policy makers, the set of economic and political constraints they face, and the costs and benefits associated with each sequence of measures. We consider that the determination of the optimal sequencing path 
requires the incorporation of these elements in the model and offers an interesting research area.

Finally, it is widely believed that a decrease in the cost of borrowing abroad, and an improving economic performance reflected in higher rates of growth and in higher market valuation of a country's assets by international investors, are good for emerging economies. Moreover, rapid growth rates usually reduce the borrowing costs faced by a country in the world markets, triggering bullish expectations. The availability of cheap foreign capital and a growing economy can effectively disguise the weakness of the financial sector, and get the financial liberalization process started, amidst the generalized optimistic environment. However, the combination of these two factors increases the country's vulnerability to a financial crisis. If financial development lags behind, the country is flirting with disaster. The experience in Asia and Latin America as well as empirical studies support this theoretical finding. ${ }^{13}$

\section{APPENDIX}

This appendix defines the equilibrium in the domestic credit market rigorously. Let's denote the set of monitoring actions $A$ available to the intermediary by $\{M, N\}$, where $M$ stands for monitoring the entrepreneur, and $N$ stands for not monitoring the entrepreneur.

Given the parameters $\left\{\phi, \beta, i_{B}, i_{L}, i_{f}, p_{H}, p_{L}\right\}$, a domestic equilibrium with intermediation is given by the choice of a monitoring action $A \in\{M, N\}$ by the intermediary, and its demand for deposits $D$ (equal to the supply of loans to the entrepreneur) such that: (E1) $D \leq$ $\bar{D}_{A}$, where the maximum amount supplied by depositors, $\bar{D}_{A}$, is given by equations (1) and (2) when $A=M, N$ respectively, and (E2) $A$ and $D$ maximize the intermediary's expected profits, which is given by equations (3) and (4) when $A=M, N$ respectively.

The following assumptions are sufficient to ensure that the upper bounds on deposits, given by equations (1) and (2), are positive, to guarantee the existence of a domestic equilibrium with intermediation, and that the demand for deposits is always greater than the maximum fully collateralized debt that the entrepreneur can afford, $E /\left(1+i_{L}\right)$ :

(A1) The intermediary's borrowing rate is at least equal to the risk-free rate, e.g., $i_{b} \geq i_{f}$.

(A2) $p_{H}\left(1+i_{B}\right)<1+i_{f}$.

(A3) $p_{L}\left(1+i_{L}\right)>1+i_{B}$.

(A4) After paying a fixed cost $\phi$, the intermediary can monitor loan sizes less or equal to $D_{\phi} \equiv E /\left(1+i_{L}\right)+E_{\phi}, E_{\phi}$ constant.

In order to understand the concept of a crash in this economy, it is useful to interpret the equilibrium as a mapping from the amount supplied by depositors into the monitoring decision and demand for deposits of the intermediary. Thus, we can define a crash-prone or crisisprone equilibrium as a discontinuous mapping from the amount supplied by depositors into the demand for deposits. Clearly, this definition implies that the demand for deposits is strictly less than the maximum amount that depositors can supply given a monitoring action by the intermediary, e.g. $D<\bar{D}_{A}$. This definition captures two important characteristics of a crisis. First, there is a credit crunch in the sense that the total supply of loans in the domestic economy falls short from the maximum available supply of deposits. Second, the existence of a discontinuous mapping implies that small changes in a number of the parameters of the economy can lead to a large change in the domestic supply of loans.

${ }^{13}$ See Demirguc-Kunt and Detragiache (1998). 


\section{CRASH-FREE SEQUENCING STRATEGIES}

It can be verified that the $\{A, D\}$ equilibrium can be one of the following six cases:

Case 1 (Crisis-Prone Equilibrium): If $\phi \leq \Delta p \Delta i D_{\phi}$ and $\beta \geq p_{H} \Delta i$, there exists a crisis-prone equilibrium, and the equilibrium is characterized by:

a) $\left\{N, \bar{D}_{u}(E)\right\}$ if $\bar{D}_{m}(E)<D_{u}$, where $D_{u}<D_{\phi}$ satisfies $\mathbf{E} \Pi^{m}\left(D_{u}\right)=\mathbf{E} \Pi^{u}\left(D_{u}\right)$.

b) $\left\{M, \min \left(\bar{D}_{m}(E), D_{\phi}\right)\right\}$ if $\bar{D}_{m}(E) \geq D_{u}$ and $\bar{D}_{u}(E)<D_{*}$, where $D_{*}$ satisfies $\mathbf{E} \Pi^{m}\left(D_{\phi}\right)=\mathbf{E} \Pi^{u}\left(D_{*}\right)$.

c) $\left\{N, \bar{D}_{u}(E)\right\}$ if $\bar{D}_{u}(E) \geq D_{*}$.

In this case, there is no intermediation in the interval $\left(D_{\phi}, D_{*}\right)$.

Case 2: If $\phi \geq \Delta p \Delta i D_{\phi}$ and $\beta \geq p_{H} \Delta i$, the equilibrium is $\left\{N, \bar{D}_{u}(E)\right\}$.

Case 3: If $\phi \leq \Delta p \Delta i D_{\phi}$ and $\Delta p \Delta i \leq \beta \leq p_{H} \Delta i$ the equilibrium is given by:

a) $\left\{N, \bar{D}_{u}(E)\right\}$ if $\bar{D}_{m}(E) \leq D_{u}$, where $D_{u}$ is the only solution to $\mathbf{E} \Pi^{m}(D)=\mathbf{E} \Pi^{u}(D)$ in the interval $\left[E /\left(1+i_{L}\right), D_{\phi}\right]$.

b) $\left\{M, \bar{D}_{m}(E)\right\}$ if $D_{u} \leq \bar{D}_{m}(E) \leq D_{m}$ and $\bar{D}_{u}(E)<D_{m}$, where $D_{u}$ was defined above and $D_{m}$ is the only solution to $\mathbf{E} \Pi^{m}(D)=\mathbf{E} \Pi^{u}(D)$ in the interval $\left[D_{\phi}, \infty\right]$.

c) $\left\{N, \bar{D}_{u}(E)\right\}$ if $\bar{D}_{u}(E)>D_{m}$.

Case 4: If $\phi \geq \Delta p \Delta i D_{\phi}$ and $\Delta p \Delta i \leq \beta \leq p_{H} \Delta i$, the equilibrium is $\left\{N, \bar{D}_{u}(E)\right\}$.

Case 5: If $\phi \leq \Delta p \Delta i D_{\phi}$ and $\beta \leq p \Delta i$, the equilibrium is given by $\left\{N, \bar{D}_{u}(E)\right\}$ if $\bar{D}_{m}(E) \leq D_{u}$, where $D_{u}$ was defined above. Otherwise the equilibrium is given by $\left\{M, \bar{D}_{m}(E)\right\}$.

Case 6: If $\phi \geq \Delta p \Delta i D_{\phi}$ and $\beta \geq \Delta p \Delta i$, the equilibrium is given by $\left\{N, \bar{D}_{u}(E)\right\}$ if $\bar{D}_{m}(E) \leq D_{m}$. Otherwise, the equilibrium is given by $\left\{M, \bar{D}_{m}(E)\right\}$.

\section{REFERENCES}

Allen, Franklin, and Douglas Gale, 2000, "Financial Contagion," Journal of Political Economy, Vol. 108, pp. 1-33.

Barajas, Adolfo, Roberto Steiner, and Natalia Salazar, 1999, "Interest Spreads in Banking in Colombia, 1974-1996," IMF Staff Papers, Vol. 46, No. 2, pp. 196-224.

Calvo, Guillermo A., and Enrique G. Mendoza, 2000, "Rational Contagion and the Globalization of Securities Markets," Journal of International Economics, Vol. 51, pp. 79-113.

Caprio, Jr., Gerard, Izak Atiyas, and James A. Hanson, 1994, Financial Reform: Theory and Experience (New York, NY: Cambridge University Press).

Chan-Lau, Jorge A., and Zhaohui Chen, forthcoming, "Financial Crisis and Credit Crunch as a Result of Inefficient Financial Intermediation-with Reference to the Asian Financial Crisis," in Review of International Economics. Available at http://papers.ssrn.com/paper.taf?abstract id=96622.

Demirguc-Kunt, Aslic, and Enrica Detragiache, 1998, "Financial Liberalization and Financial Fragility," IMF Working Paper 98/83 (Washington: International Monetary Fund).

Dooley, Michael P., 1996, "A Survey of the Literature on Controls over International Capital Transactions," IMF Staff Papers, Vol. 43, No. 4, pp. 639-87.

Eichengreen, Barry, and Michael Mussa, with Giovanni Dell'Ariccia, Enrica Detragiache, Gian Maria Milesi-Ferretti, and Andrew Tweedie, 1999, Capital Account Liberalization: Theoretical and Practical Aspects, IMF Occasional Paper No. 172 (Washington: International Monetary Fund). 


\section{Jorge A. Chan-Lau and Zhaohui Chen}

Goldsmith, Raymond, 1969, Financial Structure and Development (New Haven, Connecticut: Yale University Press).

Kolari, James, and Asghar Zardkoohi, 1987, Bank Costs, Structure and Performance, (Cambridge, Massachusetts: Lexington Books).

Johnston, R. Barry, 1991, "Sequencing Financial Sector Reform," in The Evolving Role of the Central Banks, ed. by P.T. Downes and R. Vaez-Zadeh (Washington: International Monetary Fund).

Levine, Ross, 1997, "Financial Development and Economic Growth: Views and Agenda," Journal of Economic Literature, Vol. 35, pp. 688-726.

McKinnon, Ronald I., 1973, Money and Capital in Economic Development (Baltimore, Maryland: Johns Hopkins University Press).

_ 1993, The Order of Economic Liberalization: Financial Control in the Transition to a Market Economy (Baltimore, Maryland: Johns Hopkins University Press).

Obstfeld, Maurice, 1996, "Models of Currency Crises with Self-Fulfilling Features," European Economic Review, Vol. 40, pp. 1037-47.

Shaw, Edward, 1973, Financial Deepening in Economic Development (Oxford: Oxford University Press). 